\title{
The Human Vehicle Interface System for Integrating and Managing the In-Vehicle Interactions with IT Devices
}

\author{
Jongwoo Choi, Hye Sun Park, Kyong-Ho Kim \\ Green Vehicle IT Research Team, Vehicle-IT Convergence Research Department, IT Convergence Technology \\ Research Laboratory, Electronics and Telecommunications Research Institute (ETRI) \\ 218 Gajeong-ro, Yuseong-gu, Daejeon, 305-700
}

\begin{abstract}
Objective: The aim of this study is to investigate the system to integrate and manage the in-vehicle interactions between the drivers and the in-vehicle mobile IT devices. Background: As the mobile IT technology is being used anywhere, the drivers are interacting with the mobile IT device on driving situations. The distraction of the driver's attention causes the car accidents. It is necessary to develop the HVI(Human Vehicle Interface System) to integrate and manage the in-vehicle interactions with IT devices. Method: The HVI System is designed not as the interfacing subject but as the supervising system to monitor the driver's status and support the driver to concentrate on the primary tasks. The HVI system collects the status information of the car and driver and estimate the driving workload. Results: The HVI system controls how to provide the output information based on the driving workload. We implemented the HVI system prototype and applied in the real vehicle with the HVI cell phone and the HVI car navigation system. Conclusion: Depending on the driving situations, the HVI system prevented the information output in dangerous situation and diversified the modality and the intensity of the output information. Application: We will extend the HVI system to be connected the other various IT devices and verity the effectiveness of the system through various experiments.
\end{abstract}

Keywords: HVI(Human Vehicle Interface), In-vehicle Interaction, Mobile devices, Interface Integration

\section{Introduction}

운전자의 인터페이스는 운전자가 자동차 내에서 상호작용 을 할 수 있는 모든 작업과 동작에 관련되어 있다. 자동차 안에서 운전자의 인터페이스는 다양한 목적에 의해서 이루 어 질 수 있고 이것은 사람마다 상황에 따라 다르게 수행된 다. 가장 기본적으로 수행되는 작업은 자동차의 운전과 관련 된 조작이지만 최근에는 사람들이 운전과 직접적으로 관련 이 없는 행동들도 차 안에서 많이 하고 있다. 이러한 행동이 문제가 되는 이유는 자동차 사고의 주요 원인이 운전자의 부 주의와 운전자의 실수에서 기인하기 때문이다. 현재 조사된
바로는 교통사고의 대부분이 운전자의 실수 및 과오로 인하 여 발생하는 것으로 조사되었으며 고속도로에서 운전자의 졸음이 사망 사고의 원인 중에 $17 \%$ 로 가장 높은 것으로 조 사되었다(National Highway Traffic Safety Administration, NHTSA).

이 같은 상황에서 최근 정보통신 기술의 발달로 인하여 다양한 IT 기기가 등장하였고 차량 환경이 IT 융합의 공간 으로 대두됨에 따라 자동차-IT 기술의 융합이 활발하게 이 루어지고 있다. 공간의 제약을 받지 않는 모바일 단말들이 자동차 안에서도 부담없이 자연스럽게 활용되고 있는 상황 이다. 그러나 운전자들이 운전 중에 IT 기기 사용하는 것은 안전성의 측면에서 문제가 된다. 미국에서는 2001년부터

Corresponding Author: Kyong-Ho Kim. Green Vehicle IT Research Team, Vehicle-IT Convergence Research Department, IT Convergence Technology Research Laboratory, Electronics and Telecommunications Research Institute (ETRI) 218 Gajeong-ro, Yuseong-gu, Daejeon, $305-700$.

Mobile: 010-6545-6486, E-mail:kkh@etri.re.kr

Copyright@2011 by Ergonomics Society of Korea(pISSN:1229-1684 eISSN:2093-8462). All right reserved. 
2007년간 운전 중에 휴대폰 문자 메시지 조작과 통화로 인 한 교통사고 사망자가 16,000 명에 해당되는 것으로 조사되 었다(Fernando A. Wilson and Jim P. Stimpson, 2010). 운 전 중에 내비게이션을 조작하는 행동도 안전 운전에 지장을 주는 위험한 행동이다. 따라서 운전 중에는 핸드폰과 내비 게이션을 조작하지 않도록 권장하고 있으며 $\mathrm{KoO}, 2009$, Road Traffic Safety Authority, 2005) 법적으로 규제하는 것도 하나의 방안으로 고려되고 있다.

그러나 이러한 규제는 근본적인 해결 방안이 될 수 없다. 미국의 젊은 층은 자동차를 구매할 때 인포테인먼트 시스템 이 자유롭게 사용되는 환경을 지지하는 것으로 파악되었다. 기본적인 전화 기능의 연계뿐만 아니라 엔터테인먼트의 기 능이 자동차 환경에서 원활하게 연결되어 동작하는 것이 자 동차를 선택하는데 하나의 기준이 되고 있는 추세이다. 이러 한 상황에서 운전자에게 IT 기기 사용을 원천적으로 봉쇄한 다는 것은 자동차-IT 융합 기술의 흐름과 패러다임을 파악 하지 못하는 행동이며 운전자의 안전 운전을 지원하면서도 적절하게 IT 기기를 제어함으로써 운전자의 편의에도 지장 을 주지 않고 안전 운전을 제공할 수 있는 인터페이스 관리 시스템이 필요한 상황이다. 운전자의 안전과 편의의 두 가지 요소를 모두 만족시킬 수 있는 인터페이스 통합 시스템에 대 한 연구가 필요하다. 이러한 시스템은 차량 내에서 이루어지 는 운전자의 행동과 패턴을 감지하고 운전자가 수행하는 다 양한 인터페이스와 관련된 입출력 정보 흐름을 파악하여 운 전자의 상황에 따라 인터페이스를 제어하는 시스템이다.

본 논문에서는 이 같은 기능을 수행하는 "운전자 친화형 지능형 HVI(Human Vehicle Interface) 통합 시스템" 설 계에 대해 설명한다. 본 시스템은 운전자가 수행하는 다양한 작업들과 운전자의 다양한 상호작용 중에서도 실제로 구현 할 수 있고 시스템에서 활용할 수 있는 요소 정보들을 고려 하여 설계되었다. 이러한 요소들을 수집하고 실시간으로 파 악하기 위한 모듈과 운전자의 운전부하 정량화 모듈과의 연 계, 운전부하에 최적화하여 멀티모달 인터랙션을 결정하는 모듈과의 연계, 그리고 입출력 관리 모듈과의 연계된 구조를 설계하여 운전자에게 지능적인 인터페이스를 제공하기 위한 시스템에 대해 설명한다.

\section{Method}

\subsection{The classification of the in-vehicle information}

자동차 안에서 운전자가 수행하는 행동은 크게 두 가지로 구분할 수 있다. 첫 번째는 운전자가 차량을 운전하는데 직 접적으로 필요한 동작이다. 자동차 운전은 운전자에게 가장
중요한 작업이므로 이것을 Primary Tasks라고 말한다. 두 번째는 운전과 직접적으로 관련이 없이 그 외에 수행하는 다양한 작업이 있다. 핸드폰 조작, 내비게이션 조작, 동승 자와의 상호작용 등이 이에 포함된다. 이것을 Secondary Tasks라고 말한다.

운전자 친화형 지능형 HVI 통합 시스템은 차량 내의 인터 페이스를 통합적으로 관리하는 것을 목적으로 한다. 그러기 위해서는 운전자가 수행하는 인터페이스에 대해 주고 받게 되는 정보들을 구분할 필요가 있다. 이 정보들로부터 운전자 가 수행하는 다양한 작업들에 대해서 분류할 수 있으며 그 작업에 소요되는 운전부하를 산출하게 된다. 운전자 친화형 지능형 HVI 통합 시스템은 운전자의 인터페이스에 대한 정 보를 "상태 정보"와 "제공 정보"로 구분한다.

"상태 정보"는 운전자가 수행하는 작업이 무엇인지 판단하 고 차량 및 운전자의 상태를 파악하기 위해 활용되는 정보이 다. 상태 정보에는 차량 상태 정보, 운전자 상태 정보, 운전 자가 특정 작업을 수행하기 위해 특정 시스템에 입력하고 출력하는 동작 정보가 해당된다.

"제공 정보"는 운전자 친화형 지능형 HVI 통합 시스템에 서 운전자에게 제공되는 출력 정보이다. 제공 정보는 운전자 의 입력에 대해 시스템이 응답을 출력하는 정보가 있고, 운 전자가 별도의 입력이 없다고 해도 상황에 따라 알림 또는 경고를 발생하는 정보가 있다.

운전자 친화형 지능형 HVI 통합 시스템은 상태 정보와 제공 정보를 관리하여 운전자에게 안전하고 편안한 인터페 이스를 제공한다. 상태 정보를 통해 차량과 운전자의 행동과 상태를 파악하고 운전자의 운전부하를 산출한다. 경고나 알 림 정보 같은 제공 정보가 발생할 경우에는, 앞서 산출된 운 전부하를 고려하여 제공 정보를 차단하거나 출력 방법을 최 적화한다. 부담이 적은 정보제공 모달을 결정하고 출력 강도 를 조절하여 운전자가 편안하고 적절하게 정보를 인지할 수 있도록 결정한다.

\subsection{Integrating method}

차량 내의 인터페이스를 통합한다는 의미를 고려하면 운 전자와 실제로 인터페이스를 수행하는 주체에 따라 2가지의 관점으로 통합 방안이 나뉘어진다. 운전자가 인터페이스를 수행하게 되는 주체를 어떻게 정의하느냐에 따라 시스템의 설계 및 배치가 달라지게 되며 이에 따라 구현의 방법에 차 이점이 존재하게 된다. 차량 내에서 운전자와 인터페이스를 수행하는 주체를 단일 시스템 하나로 통합한다는 관점, 그리 고 인터페이스는 기존의 방식대로 별도로 정보제공기기에서 수행하지만 관리 시스템이 이러한 인터페이스들을 모니터링 하고 관리한다는 관점이 있다. 


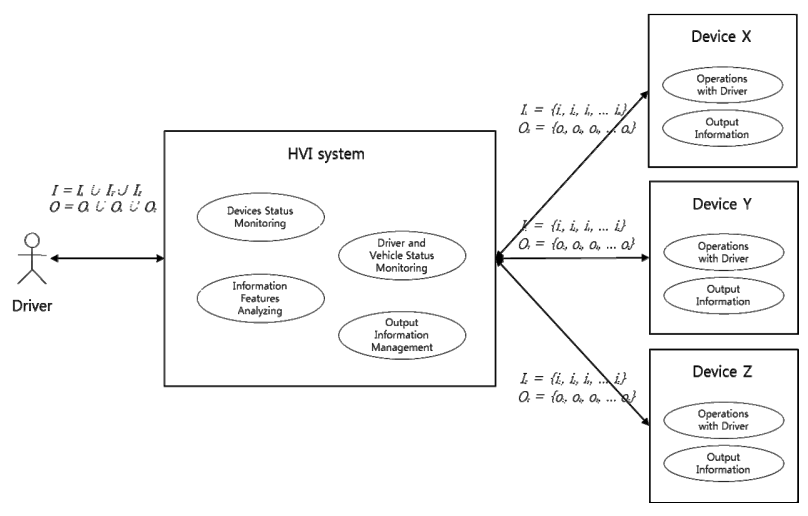

Figure 1. The HVI system as the interacting subject

첫 번째 방법은 차량 내에서 다양한 기기가 존재하더라도 인터페이스를 하는 주체가 하나가 되는 단일 인터페이스 방 식의 통합이다. 차량 내에 모든 인터페이스를 통합하는 단일 시스템이 존재하고 이 시스템은 정보를 운전자에게 전달해 주는 게이트웨이 역할을 수행한다. 차량 내의 다양한 정보제 공기기가 통합 시스템과 연결되어 있고 모든 입출력은 통합 시스템을 거치게 되는 구조이다. 따라서 운전자는 차량에서 는 오직 통합 인터페이스 시스템과 입력과 출력을 주고받고 그 외의 정보제공기기와의 작업은 통합 시스템을 거쳐서 수 행하는 방식의 통합이다.

AIDE 프로젝트(AIDE, Subproject 3.4.3: Integration of Nomadic Devices)는 이와 같이 nomadic device에 대한 게이트웨이 형태로 시스템을 설계하여 정보제공기기의 입출 력을 관리한다. 통합 시스템이 정보제공기기로부터의 입력과 출력에 대한 모든 정보를 취합하고 정보제공의 시점과 순서 등을 일괄적으로 관리하게 된다. 이와 같은 통합 방식은 인 터페이스 통합 시스템의 통제 하에 있는 차량 내의 정보제 공기기들을 원하는 방식대로 제어할 수 있다는 장점이 있으 나 현실적으로 구현하기에는 어려움이 있다. 각 정보제공기 기가 제공하는 입출력에 대한 특성을 하나의 인터페이스 통 합 시스템에서 똑같이 제공할 수가 없기 때문이다. 특정 정 보제공장치에서 제공하는 입력과 출력의 종류를 아래와 같 이 정의하면,

Device X에 대하여,

Input set $I_{X}=\left\{i_{1}, i_{2}, i_{3}, \cdots i_{m}\right\}$

Output set $O_{X}=\left\{O_{1}, O_{2}, O_{3}, \cdots O_{n}\right\}$

Device Y에 대하여,

Input set $I_{Y}=\left\{i_{1}, i_{2}, i_{3}, \cdots i_{S}\right\}$

Output set $O_{Y}=\left\{O_{1}, O_{2}, O_{3}, \cdots o_{t}\right\}$

위와 같이 Device $\mathrm{X}$ 는 $\mathrm{m}$ 개의 입력과 $\mathrm{n}$ 개의 출력을 제공
하고 Device $\mathrm{Y}$ 는 $\mathrm{s}$ 개의 입력과 $\mathrm{t}$ 개의 출력을 제공한다. 위 의 정보제공장치들의 인터페이스를 통합하기 위해서는 통합 시스템에서는 Device X, Y의 모든 입출력이 통합 시스템을 통해 운전자에게 제공되어야 한다. 통합 시스템이 Device $\mathrm{X}, \mathrm{Y}$ 의 모든 입출력을 일단 구현한다고 해도 Device X, Y 와 같은 용도의 타 제품 Device A, B로 교체되거나 새로운 장치가 등장하였다면 확장성과 호환성의 측면에서 문제가 생긴다. 새로운 장치의 입출력을 통합 시스템에서 재구성해 야 하므로 입출력이 변화하는 환경에 자동으로 대응할 수 없 다. 이러한 시스템 통합 방안은 이상적으로 인터페이스를 통 합하는 방안이 될 수 있으나 현실적으로 시스템을 구현하기 에는 어려움이 많다.

두 번째 설계 방법은 위와 같은 방법을 개선하기 위한 방 법으로 차량 내의 다양한 정보제공기기가 운전자와 인터페 이스를 하되, 배후에 통합 관리 시스템이 정보제공기기의 입 출력을 관찰하고 관리하는 방식의 통합이다. 인터페이스를 통합적으로 관리하는 개념의 설계 방식으로 통합 관리 시스 템은 운전자와 인터페이스를 주고받는 동작을 최소화하고 그 외의 입출력은 정보제공기기가 기존의 방식으로 운전자 와 주고받게 된다. 기존 인터페이스와 차이점은 정보제공기 기가 운전자의 상황을 고려하여 입출력 동작을 수행하는 것 이다. 정보제공기기는 운전자에게 정보를 제공하기 전에 통 합 인터페이스 관리 시스템과 인터페이스 관리를 위한 절차 를 수행한다.

통합 인터페이스 관리 시스템은 운전자의 상태와 차량의 상태를 주기적으로 모니터링하고 있으며 차량 내 정보제공 기기의 조작 상태를 주기적으로 관찰하고 있다. 운전 중에 차량 내 정보제공기기에서 운전자에게 제공할 정보가 발생 하면 정보제공기기는 즉각 운전자에게 정보를 제공하지 않 고 통합 인터페이스 관리 시스템에게 운전자에게 제공할 정 보가 있음을 알리면서 동시에 그 정보의 속성 및 중요도에 대해서도 전달한다.

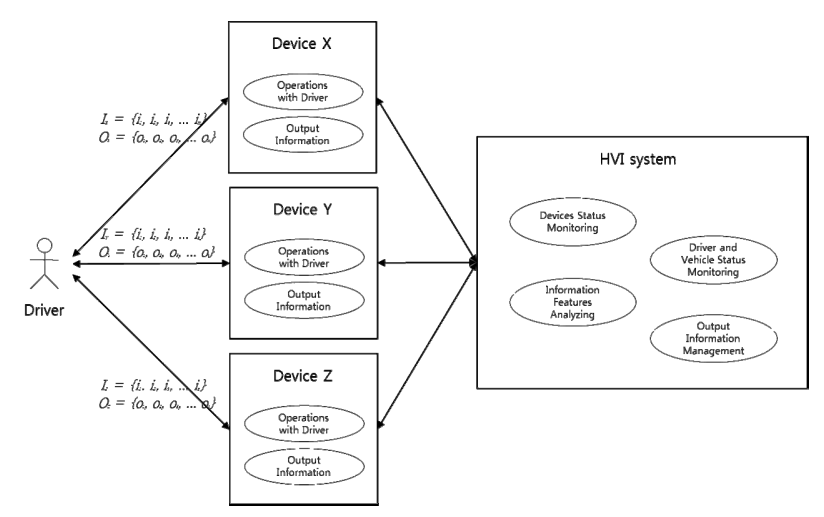

Figure 2. The HVI system as the interface manager 
통합 인터페이스 관리 시스템은 정보의 속성과 중요도를 확인하고 운전자와 차량의 상태에 따라 정보를 제공할지 차 단할지 결정하게 된다. 필요에 따라서는 정보의 제공을 지연 시키도록 한다. 또한 운전부하에 따라 운전자가 정보를 안전 하고 편안하게 인지할 수 있는 모달을 선택하고 정보제공 강 도를 결정하여 정보제공기기에 응답한다. 정보제공기기는 통 한 인터페이스 관리 시스템의 결정에 따라 운전자에게 정보 를 제공한다. 이와 같이 인터페이스를 관리한다는 관점에서 의 통합은 기존의 차량 내 정보제공기기를 크게 바꾸지 않고 호환성을 유지하면서도 구현이 용이한 형태이고 또한 새로 운 장치가 추가되거나 변경되는 경우에도 확장이 가능한 유 연한 구조이다. 현실적으로 이러한 형태의 통합이 다양한 정 보제공기기를 통합적으로 관리하고 새로운 장치에 적응하기 에 적절한 형태이다. 따라서 본 논문에서는 운전자 친화형 지능형 HVI 통합 시스템은 이와 같은 관점으로 차량 내 정 보제공기기 연계 구조를 설계하였다.

\section{HVI(Human Vehicle Interface) System}

운전자 친화형 지능형 HVI 통합 시스템은 운전자와 직접 인터페이스를 수행하지 않는다. 겉으로는 드러나지 않지만 차량 내 정보제공기기들의 인터페이스를 통합적으로 관리하 는 시스템이다. 운전자 친화형 지능형 HVI 통합 시스템의 구조는 차량 및 운전자 상태를 감지하기 위한 센싱 장치와의 연계 및 차량 내 정보제공기기로써 대표적인 핸드폰과 내비 게이션과 연계하여 인터페이스 관리 기능을 수행하기 위한 시스템 구조이다. 운전자 친화형 지능형 HVI 통합 시스템은 차량 및 운전자의 상태를 감지하는 기능, 운전자의 운전부하 를 측정하고 정량화하는 기능, 운전부하에 맞게 정보를 지능 적으로 제공하는 기능을 수행한다.

\subsection{Vehicle and driver status information}

운전자에게 적합한 인터페이스를 제공하기 위해서는 운전 자와 차량의 상태를 파악해야 한다. 차량과 운전자의 상태 정보를 수집하기 위해서는 차량의 상태와 운전자의 상태를 감지할 수 있는 센싱 장치가 필요하다. 기본적인 차량 정보 는 자동차에 탑재된 $\mathrm{OBD}-\mathrm{II}$ 포트를 통해 수집되는 정보를 활용한다. $\mathrm{OBD}-\mathrm{II}$ 포트를 통해서 수집되는 정보에는 다양한 차량 정보가 있는데 차량의 진단 정보, 상태 및 운행 정보 로 구분된다. 차량의 진단 정보인 DTC(Diagnostic Trouble Codes)는 차량의 고장 상태를 나타내는 코드로 구성되어 있다. DTC를 통해서 차량의 어느 부분에 고장이 발생했는지
확인할 수 있으며 자동차 정비소에서 이 정보를 유용하게 사 용한다. 그러나 DTC 정보는 운전자의 작업을 파악하는데 사용되는 정보는 아니다. 차량의 상태 및 운행 정보가 운전 자의 작업을 파악하기 위해 활용되는 정보이며, 운행 중에 차량의 속도, $\mathrm{RPM}$, 냉각수 온도, 브레이크 페달 $\mathrm{ON} / \mathrm{OFF}$, 스로틀 포지션, 조향휠 각도, 연료분사시간, 기어단 등의 정 보가 해당된다. 이 정보는 차량의 운행과 직접적인 관련이 있 으므로 이로부터 운전자의 Primary task를 파악할 수 있다. 운전자 친화형 지능형 HVI 통합 시스템은 차량 정보 센싱 장치와 연계하여 차량 정보를 분석하여 운전자의 Primary Tasks를 판단한다.

운전자의 상태 정보는 신체적인 정보를 수집하여 추출해 야 하므로 생체 정보 센싱 장치를 설치해야 한다. 운전자의 시선을 추적하는 Eye tracker와 체온, 맥박, 심전도, 뇌파, 혈류량을 측정하는 생체 정보 측정장비를 설치하면 운전자 의 신체적인 상태를 수집할 수 있다. 운전자 친화형 지능형 HVI 통합 시스템은 이 같은 차량정보와 운전자 정보를 센싱 장치로부터 수신하여 운전부하를 산출하고 활용할 수 있다.

\subsection{Interactions with in-vehicle IT devices}

운전자 친화형 지능형 HVI 통합 시스템은 차내 정보 제공 기기의 인터페이스를 통합 관리한다. 본 논문에서는 차내 정 보제공기기 중에 사용자들이 가장 많이 사용하고 있는 핸드 폰과 내비게이션과 관련된 인터페이스를 통합하여 관리하기 위한 연계 구조에 대해 설명한다. 앞서 설명한 바와 같이 차 내 정보제공기기의 입출력 정보들은 상태 정보와 제공 정보 로 구분된다.

먼저 핸드폰에서의 정보를 고려하면, 핸드폰의 상태 정보 는 운전자가 핸드폰을 사용함에 따른 Secondary Tasks와 관련된 정보이다. 전화를 거는 행동, 문자 메시지를 송신하 고 확인하는 행동, 폰 애플리케이션을 사용하는 행동과 관련 이 있다. 핸드폰은 주기적으로 운전자 친화형 지능형 HVI 통합 시스템에게 운전자의 조작과 관련된 상태 정보를 전송 한다. 핸드폰의 제공 정보는 핸드폰이 운전자에게 비동기적 으로 제공하는 정보로서 전화 수신, 문자 메시지 수신과 관 련된 알림 정보가 해당된다. 핸드폰은 제공 정보를 운전자에 게 제공하기 전에 운전자 친화형 지능형 HVI 통합 시스템에 게 인터페이스 관련 사항에 대해 전달한다. 전화/문자 메시 지를 구분하기 위한 정보와 발신자에 따른 정보의 중요도이 다. 운전자 친화형 지능형 HVI 통합 시스템은 운전자의 상 황과 운전부하를 감안하여 운전자가 정보를 수신할 수 있는 지 판단하여 핸드폰에게 정보제공 여부를 응답한다.

내비게이션 인터페이스 관련 정보도 상태 정보와 제공 정 보로 구분하게 된다. 내비게이션과 관련된 상태 정보도 운전 
Table 1. Interactions with the cell phone

\begin{tabular}{c|c}
\hline $\begin{array}{c}\text { Interactions with } \\
\text { the cell phone }\end{array}$ & Description \\
\hline $\begin{array}{c}\text { Operational status } \\
\text { information }\end{array}$ & $\begin{array}{c}\text { The driver's tasks related with the cell phone } \\
\text { are derived from the operations } \\
\text { of the cell phone. }\end{array}$ \\
$\begin{array}{c}\text { The operations with the cell phone are } \\
\text { "sleep", "make a call", "send/check SMS", } \\
\text { "other input" to "use applications". }\end{array}$ \\
\hline $\begin{array}{c}\text { Receiving the } \\
\text { phone call }\end{array}$ & $\begin{array}{c}\text { The cell phone asks to the HVI management } \\
\text { system to answer the phone call }\end{array}$ \\
\hline $\begin{array}{c}\text { Receiving the } \\
\text { SMS message }\end{array}$ & $\begin{array}{c}\text { The cell phone asks to the HVI management } \\
\text { system to notify the driver that SMS } \\
\text { message is received }\end{array}$ \\
\hline
\end{tabular}

자가 내비게이션을 조작하면서 수행하는 Secondary Tasks 와 관련이 있다. 운전자가 내비게이션 맵의 위치를 클릭하고 스케일을 조정하는 행동, 내비게이션의 메뉴를 클릭하여 경 로 검색, 부가 기능, 환경 설정의 기능을 수행하는 행동이다. 내비게이션은 운전자 친화형 지능형 HVI 통합 시스템에게 내비게이션 조작에 대한 이벤트 정보를 전달한다. 내비게이 션은 기존에도 자동차 환경을 고려하여 설계된 IT 기기이므 로 차량과 관련된 유용한 상태 정보를 획득할 수 있다. 내비 게이션은 지도 정보와 경로 상태 정보를 가지고 있는데 현 재 주행하고 있는 도로의 속성과 운행 구간의 상태에 대한

Table 2. Interactions with the car navigation system

\begin{tabular}{c|c}
\hline $\begin{array}{c}\text { Interactions with the } \\
\text { car navigation system }\end{array}$ & Descrpition \\
\hline $\begin{array}{c}\text { Operational status } \\
\text { information }\end{array}$ & $\begin{array}{c}\text { The driver's tasks related with the car } \\
\text { navigation system are derived from the } \\
\text { operations of the car navigations system. } \\
\text { The operations with the car navigation } \\
\text { systems are the "basic map", "menu", } \\
\text { "search the path", "set the configurations" }\end{array}$ \\
\hline $\begin{array}{c}\text { Driving situations } \\
\text { information }\end{array}$ & $\begin{array}{c}\text { The features of the path(highway, } \\
\text { national road, trunk road) and } \\
\text { the features of the section }\end{array}$ \\
\hline $\begin{array}{c}\text { The information to } \\
\text { be provided to } \\
\text { the driver }\end{array}$ & $\begin{array}{c}\text { The routing information, POI } \\
\text { (Point of Interest), Warning }\end{array}$ \\
\hline $\begin{array}{c}\text { Modality selection } \\
\text { and intensity } \\
\text { adjustment }\end{array}$ & $\begin{array}{c}\text { The car navigation asks the HVI } \\
\text { mangement system how to represent the } \\
\text { navigation information, then the HVI } \\
\text { management system selects the modality } \\
\text { and decides the intensity to provide the } \\
\text { information by the driver's status. }\end{array}$ \\
\hline
\end{tabular}

정보는 운전자의 상태를 파악하는데 도움이 되는 정보이다. 내비게이션은 이 같은 경로 상태 정보를 운전자 친화형 지 능형 HVI 통합 시스템에게 전달한다. 내비게이션이 운전자 에게 제공하는 정보는 경로와 관련된 안내 정보와 위치에 기반한 $\mathrm{POI}$ 정보, 과속 정보, 단속 정보와 같은 알림 정보들 이다. 내비게이션은 제공 정보를 제공하기에 앞서 운전자 친 화형 지능형 HVI 통합 시스템에게 정보 속성을 전달한다. 운전자 친화형 지능형 HVI 통합 시스템은 운전 상황과 운 전부하에 따라 정보제공 여부를 판단하고 운전자가 정보를 부담없이 인지할 수 있는 모달을 선택하며 정보제공의 강도 를 결정하여 응답한다. 그러면 내비게이션에서 응답된 정보 를 기반으로 운전자에게 정보를 제공한다.

\section{Results}

운전자 친화형 지능형 HVI 통합 시스템은 차량 정보 센싱 장치, 핸드폰, 내비게이션과 연계되어 프로토타입 시스템이 구성되었다. 실제 차량에 본 프로토타입을 설치하여 운행을 수행하였다. 차량 정보는 $\mathrm{OBD}-\mathrm{II}$ 포트와 연결되는 하드웨 어와 내부의 Firmware로 구성되어 있다. RS232 통신으로 운전자 친화형 지능형 HVI 통합 시스템에게 차량 정보를 전 달한다. 핸드폰은 최근 기술의 흐름에 따라 Android 플랫폼 의 스마트폰에서 동작하도록 구글의 레퍼런스 폰인 넥서스 원에서 구현하였다. 핸드폰과 운전자 친화형 지능형 HVI 통 합 시스템은 블루투스 통신을 활용하여 데이터를 주고받는 다. 내비게이션은 상용 내비게이션 소프트웨어와 연동되도록 윈도우즈 $\mathrm{CE}$ 기반의 메시지로 구성하였다. 운전자 친화형 지능형 HVI 통합 시스템은 차량용 단말 시스템에서 차량 내 에서 주고받는 정보들을 관리하는 소프트웨어로 구현되었다. 차량 내의 센싱 장치와 정보제공기기와 연동하기 위한 모듈, 운전부하 산출 라이브러리, 멀티모달 인터페이스 결정 모듈, 입출력 정보 관리 모듈로 구성된다. 실제 차량에 운전자 친 화형 지능형 HVI 통합 시스템을 설치하여 주행을 해보면서 다양한 정보를 발생시켜 보았다. 자동차에서 우회전을 수행 하고 있을 때 외부 전화가 수신되면 운전자 친화형 지능형 HVI 통합 시스템과 연계하여 핸드폰에서 전화를 차단하고 발신자에게 지금은 운전 중이라 전화를 수신할 수 없음을 알려준다. 차량이 정차하거나 직진 정속 주행을 하는 안전한 상황으로 전환되면 핸드폰은 운전 중에 전화가 차단되었음 을 알린다. 내비게이션 정보는 시각 정보와 청각 정보의 등 급을 다르게 하여 운전자에게 제공된다. 운전자의 운전부하 에 따라 자극적인 색상의 화면을 제공하거나 음성 알림의 크 기를 다양하게 변화하여 정보를 제공한다. 


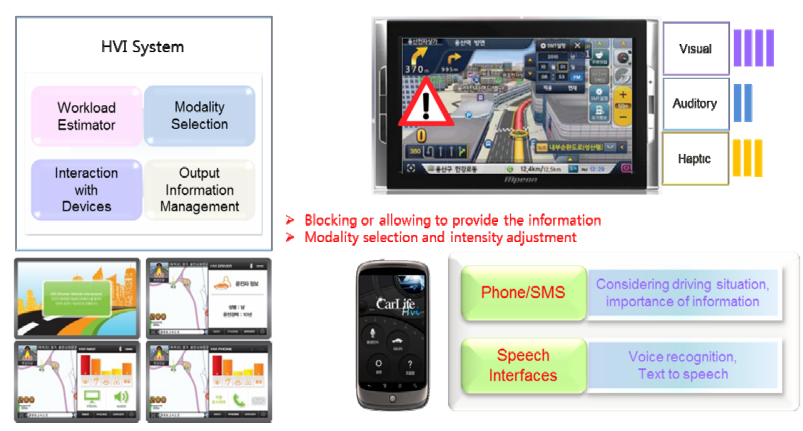

Figure 3. HVI system application

운전자 친화형 지능형 HVI 통합 시스템이 핸드폰과 내비 게이션과 연계되어 구성되었고 실차에서 HVI 기능이 수행 되는 것을 확인하였다.

\section{Conclusion}

자동차에서 운전자에게 안전하고 편안한 인터페이스를 제 공하기 위해서는 운전자가 수행하는 작업 (Primary tasks, Secondary tasks)을 파악하고 운전 상황 및 운전부하에 따 라 입출력 정보를 관리해야 한다. 본 논문에서는 차량 내에 서 인터페이스를 통합하기 위한 방안과 운전자 친화형 지능 형 HVI 통합 시스템에 대해 소개하였다. 운전자 친화형 지 능형 HVI 통합 시스템은 운전자와 직접 인터페이스를 하지 않지만 차량 내에서 주고받는 정보들을 관리하여 인터페이 스 통합을 이룬다. 인터페이스와 관련된 정보를 상태 정보와 제공 정보로 구분하였고 차량 및 운전자 상태 정보를 수집하 고 차내 정보제공기기에 대해서 운전자의 작업을 유추하기 위한 정보와 운전자에게 제공할 정보를 연동하여 시스템을 설계하였다.

운전자 친화형 지능형 HVI 통합 시스템은 보편적으로 많 이 사용되는 IT 기기인 핸드폰, 내비게이션과 연계되었고 프 로토타입이 구현되었다. 프로토타입을 실차량에 장착하고 운 행하면서 다양한 정보를 발생하였는데 운전 상황에 따라 정 보를 차단하고 정보제공 방법을 달리하는 것을 확인하였다. 본 시스템의 적용을 통해 운전 환경에서 주의 분산을 최소화 하고 운전자와 차량의 상태에 맞게 최적화된 정보제공이 가 능할 것으로 예상된다. 향후 실제 운전자를 대상으로 운전자 친화형 지능형 HVI 통합 시스템의 효용성 및 사용자 만족도 를 조사하여 효과를 검증하고 그 결과를 기반으로 시스템의 안정성 및 정확성을 개선할 것이다.

\section{Acknowledgements}

This work was supported by the Industrial Strategic Technology Development Program and the Development of Driver Adaptive Intelligent HVI(Human-Vehicle Interface) Technology(10033346) funded by the Ministry of Knowledge Economy(MKE, Korea).

\section{References}

AIDE - Adaptive Integrated Driver-vehicle Interface: www.aide-eu.org Am J Public Health, Nov 100, 2213-2219, 2010.

Choi, J., Park, H., Park, J. and Kim, K., "The Human-Vehicle Interface System for Integrating the Interaction based on the in-vehicle Information Level", Automotive UI, 2010.

Fernando A. Wilson and Jim P. Stimpson, Trends in Fatalities From Distracted Driving in the United States, 1999 to 2008, American Public Health Association, Nov 100, 2213-2219, 2010.

Furness, T. A. and Kocian, D. F., "Putting Humans into Virtual Space", Proceedings of the 16th Conference on Aerospace Simulation, 2 (pp. 48-52), San Diego. CA. 1986.

Hoedemaeker, M. and Neerincx, M. A., Attuning In-Car User Interfaces to the Momentary Cognitive Load. In: Schmorrow, D.D., Reeves, L.M. (eds.) HCII 2007 and FAC 2007. LNCS, vol. 4565, pp. 286-293. Springer, Heidelberg (2007).

Karhu, O., Kansi, P. and Kuorinka, I., Correcting working postures in industry: a practical method for analysis, Applied Ergonomics, 8(4), 199-201, 1977.

Klauer, S. G., The impact of driver inattention on near-crash/crash risk: an analysis using the 100-car naturalistic driving study data. NHTSA, Washington (2006).

Kwon, H.-J., Kim, D.-J., Park, H.-S., Kim, K.-H. and Hong, K.-S., A Method for Evaluation of in-vehicle Information Level for Driving Workload Optimization. In: Proc. of the Summer Conference of Korea Institute of Signal Processing and Systems, vol. 11(1), pp. 178-181, 2010.

Koo, T.-Y., Park, K.-J., Kim, B.-Y., Kim, H.-J. and Suh, M.-W. "A Study on Driver's Workload of Telematics using Driving Simulator-A Comparison among Information Modalities", International Journal of Precision Engineering and Manufacturing, Vol.10, No.3, (pp.59-63), 2009.

McKnight, J. and McKnight, S., The effect of cellular phone use upon driver attention. Accidents Analysis and Prevention 25, 259-265, 1991.

Rino, F. T., Brouwer, Marieka Hoedemaeker, and Mark A. Neerincx, "Adaptive Interfaces in Driving", Foundations of Augmented Cognition. Neuroergonomics and Operational Neuroscience Lecture Notes in Computer Science, 2009, Volume 5638/2009, 13-19.

Road Traffic Safety Authority (South Korea): Statistical Analysis of Traffic 
Accident: RTSA Annual Report, (pp. 61-70), 2005.

Verwey, W. B., On-line driver workload estimation. Effects of road situation and age on secondary task measures. Ergonomics, 43(8), 187-209, 2000.

Wiliges, R. C., Design of Human-Computer Dialogues. In G. Salvendy (Ed), Human-Computer Interaction, Elsevier, Amsterdam, 125-153, 1984.

Woodson, W. E., et al. Human Factors Design Handbook, 2nd ed., McGrawHill, 1992.

\section{Author listings}

Jongwoo Choi: jwchoi@etri.re.kr

Highest degree: MS, School of Electrical Engineering and Computer Science, Seoul National University

Position title: Member of Engineering Staff, Green Vehicle IT Research Team, Vehicle-IT Convergence Research Department, IT Convergence Technology Research Laboratory, Electronics and Telecommunications Research Institute (ETRI)

Areas of interest: Human Vehicle Interface System, Real-time Operating System, Embedded Systems
Hye Sun Park: hspark78@etri.re.kr

Highest degree: $\mathrm{PhD}$, Department of Computer Science and Engineering, Kyungpook National University

Position title: Senior Engineer, Green Vehicle IT Research Team,

Vehicle-IT Convergence Research Department, IT Convergence

Technology Research Laboratory, Electronics and Telecommunications Research Institute(ETRI)

Areas of interest: $\mathrm{HCI}($ Human Computer Interaction), Computer Vision, Pattern Recognition, Human Behavior

Kyong-Ho Kim: kkh@etri.re.kr

Highest degree: $\mathrm{PhD}$, Department of Computer Science, KAIST Position title: Team leader, Green Vehicle IT Research Team, Vehicle-IT Convergence Research Department, IT Convergence Technology Research Laboratory, Electronics and Telecommunications Research Institute (ETRI)

Areas of interest: $\mathrm{HCI}($ Human Computer Interaction), Virtual Reality, Augmented Reality

Date Received : 2011-07-18

Date Revised : 2011-07-29

Date Accepted : 2011-08-02 